OPEN ACCESS

Edited by:

Miguel Arenas,

University of Vigo, Spain

Reviewed by:

Isabel M. Alves,

INSERM U1087 L'unité de recherche de l'institut du thorax, France

Rita Rasteiro,

University of Bristol, United Kingdom

Simon T. Maddock,

University of Wolverhampton,

United Kingdom

*Correspondence:

Daniel Pacheco Bruschi

danie/pachechecobruschi@gmail.com

Specialty section:

This article was submitted to

Evolutionary and

Population Genetics,

a section of the journal

Frontiers in Genetics

Received: 24 August 2018

Accepted: 11 July 2019

Published: 14 August 2019

Citation:

Bruschi DP, Peres EA, Lourenço LB, Bartoleti LFdM, Sobral-Souza T

and Recco-Pimentel SM (2019)

Signature of the Paleo-Course Changes in the São Francisco River

as Source of Genetic Structure in Neotropical Pithecopus nordestinus (Phyllomedusinae, Anura) Treefrog.

Front. Genet. 10:728.

doi: 10.3389/fgene.2019.00728

\section{Signature of the Paleo-Course} Changes in the São Francisco River as Source of Genetic Structure in Neotropical Pithecopus nordestinus (Phyllomedusinae, Anura) Treefrog

\author{
Daniel Pacheco Bruschi 1*, Elen Arroyo Peres², Luciana Bolsoni Lourenço ${ }^{3}$, \\ Luiz Filipe de Macedo Bartoleti ${ }^{4}$, Thadeu Sobral-Souza ${ }^{5}$ and Shirlei Maria Recco-Pimente/ ${ }^{3}$

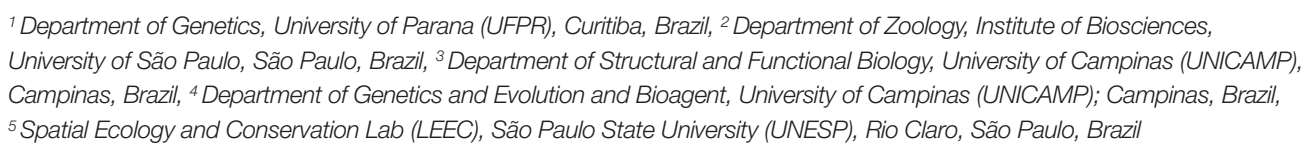

${ }^{1}$ Department of Genetics, University of Parana (UFPR), Curitiba, Brazil, ${ }^{2}$ Department of Zoology, Institute of Biosciences, University of São Paulo, São Paulo, Brazil, ${ }^{3}$ Department of Structural and Functional Biology, University of Campinas (UNICAMP), Campinas, Brazil, ${ }^{4}$ Department of Genetics and Evolution and Bioagent, University of Campinas (UNICAMP); Campinas, Brazil, ${ }^{5}$ Spatial Ecology and Conservation Lab (LEEC), São Paulo State University (UNESP), Rio Claro, São Paulo, Brazil

Historical processes that have interrupted gene flow between distinct evolutionary lineages have played a fundamental role in the evolution of the enormous diversity of species found in the Neotropical region. Numerous studies have discussed the role of geographic barriers and Pleistocene forest refugia in the diversification of the region's biodiversity. In the present study, we investigated the relative contribution of these different factors to the evolutionary history of Pithecopus nordestinus, a Neotropical tree frog, which is amply distributed in the Brazilian Atlantic Forest and adjacent areas of the Caatinga biome. We used an extensive sample and multilocus DNA sequences to provide an overview of the intraspecific genetic diversity of $P$. nordestinus, characterize historical diversification patterns, and identify possible phylogenetic splits. We tested different scenarios of diversification based on Pleistocene Refugia and river barrier models using approximate Bayesian computation (ABC) and ecological niche modeling (ENM). The phylogenetic approach indicate the occurrence of processes of phylogeographic divergence in both time and space, related to historical shifts in the course of the São Francisco River during Plio-Pleistocene period, resulting in two principal, highly divergent clades. The ABC model provided strong statistical support for this scenario, confirming the hypothesis that the São Francisco River acted as an effective geographical barrier during vicariant events in the evolutionary history of $P$. nordestinus. We believe that the climatic changes that occurred during the Pleistocene also played a secondary role in the genetic signatures identified, reinforcing the divergence of populations isolated by physical barriers. These findings reinforce the conclusion that the two models of diversification (geographic barriers and refugia) are not mutually exclusive in the Neotropical domain but may interact extensively during the diversification of species on a regional scale.

Keywords: Anura, vicariance, Riverine barrier hypothesis, phylogeographic break, allopatric diversification 


\section{INTRODUCTION}

Models of speciation are widely invoked to explain the origin and diversification of lineages and species complexes in the Brazilian Atlantic Forest, a global hotspot. As the Atlantic Forest presents high species richness, endemism, different phytophisionomies, and a complex topographic landscape (Turchetto-Zolet et al., 2013), it has long been a target for the investigation of the evolutionary processes that promote lineage divergences in several taxa (Carnaval et al., 2009; Thomé et al., 2014; Álvarez-Presas et al., 2014; Magalhães et al., 2014; Peres et al., 2018).

A range of organisms present high geographically associated genetic structure in different areas of Atlantic Forest, reflecting historical discontinuities in gene flow (Álvarez-Presas et al., 2014; Menezes et al., 2016; Frantini-Silva et al., 2017); however, the origin of these allopatric processes remains unclear. Two main sources of vicariance have been proposed: i) the isolation of populations and reduction of gene flow through the formation of geomorphological barriers (Amaral et al., 2013; Thomé et al., 2014; Cazé et al., 2016; Peres et al., 2018) and ii) habitat fragmentation resulting from historical climatic changes during the (Pleistocene Refuges Hypothesis; Haffer, 1969; Vanzolini and Williams, 1981), restricting gene flow among fragments (Carnaval et al., 2009; Menezes et al., 2016).

Phylogeographic studies with different taxa report genetic breaks spatial or temporally congruent with specific geomorphological features of the Atlantic Forest (as rivers or mountain ranges), which have been highlighted to explain intra- and/or interspecific diversification of lizards (e.g., Werneck et al., 2015), rodents (Nascimento et al., 2011; Nascimento et al., 2013), amphibians (Thomé et al., 2010), plants (Cazé et al., 2016), harvestmen (Peres et al., 2018), and many other groups. In several lowland species, the phylogeographic patterns can be explained by the Riverine Barrier hypothesis, initially proposed by Wallace (1852), which establishes that rivers are effective barriers to gene flow between populations on opposite margins, resulting in their isolation and genetic differentiation along time (Amaral et al., 2013; Cazé et al., 2016). According to this hypothesis' predictions, lower levels of genetic differentiation would be expected among populations from the same margin, species from opposite river margins would be typically sister taxa, and the timing of divergence events would coincide with the geological changes in the landscape (Moritz et al., 2000).

The genetic signatures associated with Pleistocene climate events, by contrast, would reflect the influence of forest relict during the Last Glacial Maximum [LGM; ca. 21,000 years ago (kya)] on allopatric diversification, as observed in many taxa (Carnaval et al., 2009; Cabanne et al., 2016; Menezes et al., 2016). Thus, if the diversification of lineages was determined by Pleistocene climate changes, the divergence times would be expected to coincide with this period; in addition, higher genetic diversity would be found in populations from areas presumed to be climatically stable (refuges), contrasting with the lower diversity in populations outside these putative refuges, which would be consistent with a genetic signature of recent demographic expansion (Carnaval et al., 2009). However, the same episode of climate shifts could impact differently the molecular diversity of organisms due to the dispersal model, demographic profile, or generation time of the species (Arenas et al., 2012; Arenas et al., 2014). Thus, to recognize the genomic signature of these events request an evaluation under speciesspecific optical (Mona et al., 2014).

The anuran Pithecopus nordestinus (Anura, Arboranae, Phyllomedusidae) is widely distributed in the Atlantic Forest and adjacent areas of Caatinga scrublands (Frost, 2019). This species represents an interesting model to test hypotheses on the respective roles of geographical barriers and forest retraction during the LGM as vicariant determinants of lineage diversification. The phylogenetic hypothesis proposed by Faivovich et al. (2010) for the Phyllomedusinae family identified divergence in the gene sequences of three widely dispersed populations of the $P$. nordestinus, with uncorrected pairwise distances ranging up to $10.4 \%$. This intraspecific diversity was spatially structured, since the most divergent populations were those from Passos do Camaragibe (Alagoas state) and Maracás (Bahia), the type locality of $P$. nordestinus (Faivovich et al., 2010). This geographical association of $P$. nordestinus sequences is consistent with the São Francisco River (SFR) delimitation, recognized as one of the main physical barriers to the dispersion of the biota in the northern Atlantic Forest. The SFR is the second largest river system in Brazil (Figure 1). Its lowest stretch separates the Brazilian states of Alagoas and Sergipe and is assumed to play an important role in the phylogeographic patterns of a number of different organisms (Siedchlag et al., 2010; Werneck et al., 2012; Nascimento et al., 2013). However, the pattern of genetic divergence described by Faivovich et al. (2010) also coincides with the distribution of the two northernmost Atlantic Forest Pleistocene refugia, the Pernambuco and Bahia centers of endemism (Carnaval and Moritz, 2008). The Pernambuco center is located in the northernmost portion of the Atlantic Forest, and it is separated from the Bahia center by the São Francisco River (Carnaval and Moritz, 2008).

To test the hypotheses on the possible historical scenarios that shaped the genetic diversity of this species, we sampled $P$. nordestinus throughout most of its geographical distribution to obtain phylogenetic inferences, genetic diversity indices, demographic patterns, and divergence times. We modeled the species potential distribution area in the present and in the past, and based on the historical species distribution and the main lineages recovered in our analyses (see Results), we designed and evaluated two biogeographic scenarios using coalescent simulations, as follows: i) SFR as a barrier to gene flow between ancient interbreeding populations currently located in opposite margins (resulting in allopatric speciation) and ii) ancient lineages diversified during Pleistocene climate shifts that created refugia, bisected populations.

\section{MATERIAL AND METHODS}

\section{Study Region and Collection of Samples}

(Figure 1A; Table S1A) of the P. nordestinus species. These samples covered $\sim 90 \%$ of the combined distribution of this species in Brazil (Figure 1). The tissue samples were extracted 


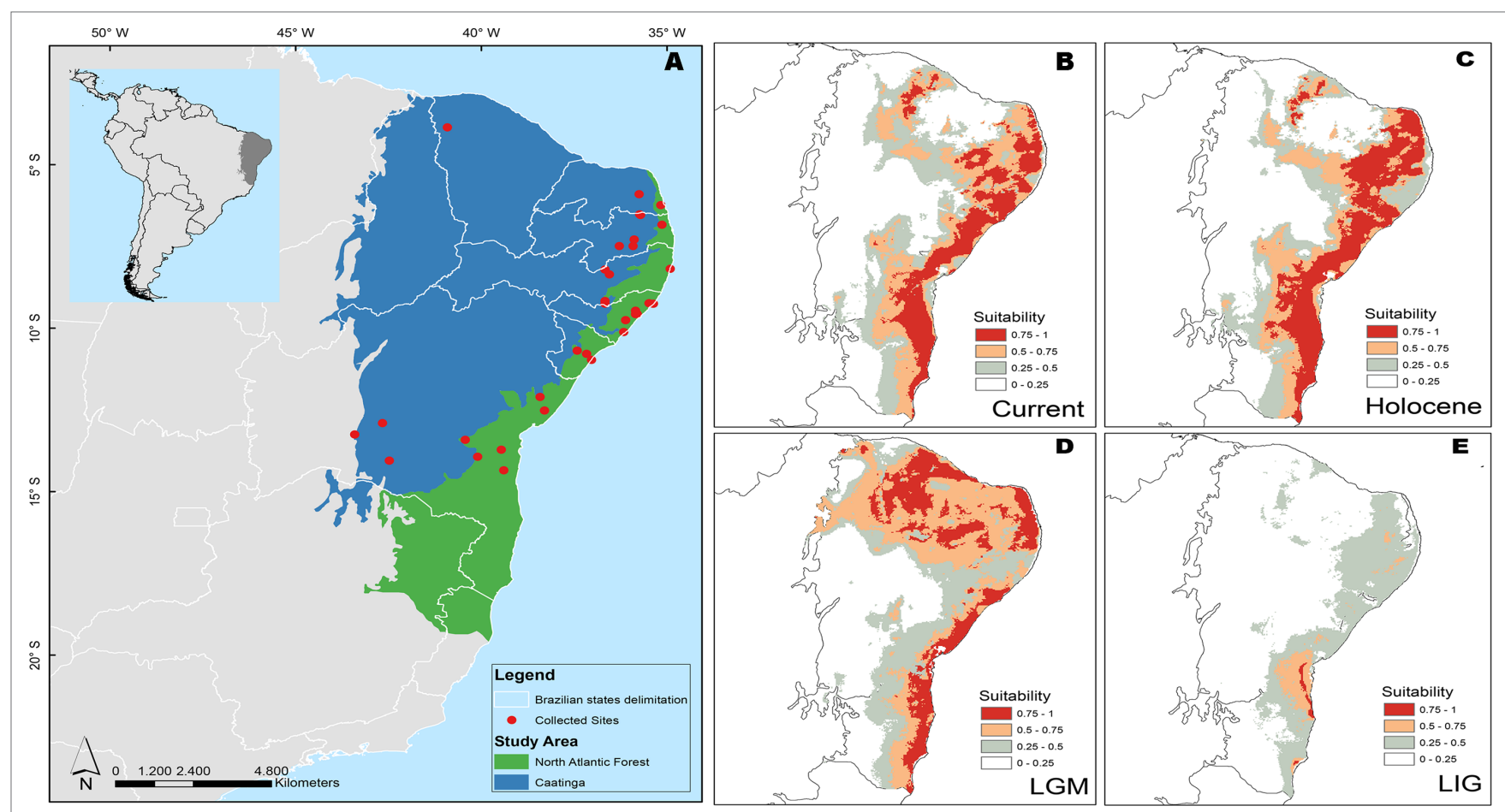

FIGURE 1 | Distribution of morphoclimatic domains and sampling localities in Brazil for specimens of $P$. nordestinus included in this study (A) and Ecological Niche Modeling (ENM) showing suitable areas for the $P$. nordestinus potential occurrence in present and past climate scenarios. ENM prediction for present day (B), during 6 ka-mid-Holocene (HOL) (C); 21 ka-Last Glacial Maximum (LGM) (D); and 120 ka-Last Interglacial Maximum (LIG) (E). See Material and Methods for more details.

from euthanized specimens using anesthetic application to the skin (5\% Lidocaine), according to recommendations of the Herpetological Animal Care and Use Committee (HACC) of the American Society of Ichthyologists and Herpetologists (available at: http://www.asih.org/publications) and approved by SISBIO/ Institute Chico Mendes de Conservação da Biodiversidade as a condition for the concession license (number 14468-1/144684). Voucher specimens were deposited in the CFBH Amphibian Collection of the Paulista State University (UNESP) in Rio Claro, São Paulo, Brazil, and the Prof. Adão José Cardoso Museum of Zoology at Campinas State University (UNICAMP) in São Paulo, Brazil (see Supporting information S1a). We used Pithecopus hypochondrialis and P. azureus, two closely related species, plus P. ayeaye, Phyllomedusa tarsius, and Callimedusa tomopterna, as three successively distant (in this order) outgroup taxa (according to Duellman et al., 2016).

\section{Extraction, Amplification, and Sequencing of the DNA}

The genomic DNA was extracted from liver and muscle tissue samples (preserved in ethanol 95\%) using the TNES method (50 mM Tris, pH 7.5, 0.4 M NaCl, 20 mM EDTA, 0.5\% SDS) (see Bruschi et al., 2012). We amplified and sequenced fragments of two mitochondrial genes, NADH dehydrogenase subunit 2 (ND2) and the ribosomal 16S gene (16S), and two nuclear loci, Rhodopsin exon 1 (Rhod) and Seven in Absentia Homolog 1 (SiaH) (primers used for each fragment are described in the Supporting information
Table S1B). The polymerase chain reactions (PCRs) were run in a total volume of $25 \mu \mathrm{l}$ containing 20-100 ng of the DNA template, $1 \times$ PCR buffer, $1.5 \mathrm{mM} \mathrm{MgCl}_{2}, 7 \mathrm{pmol} / \mu \mathrm{l}$ of the forward and reverse primers, $1 \mathrm{mM}$ of dNTPs, and $1 \mathrm{U}$ of Taq polymerase. The amplicons were purified with exonuclease I (10 units) and SAP (1 unit) to remove unincorporated dNTPs and primers. Fragments were sequenced in an ABI PRISM 3100 Genetic Analyzer (Applied Biosystems, Foster City, CA, USA) in both directions, using the original amplification primers and BigDye terminator sequencing chemistry according to the manufacture's protocol (Applied Biosystems, Foster City, CA, USA).

\section{Alignment and Phasing of the Nuclear Sequences}

The sequences were inspected and edited in CodonCode Aligner 7.1.1. The $16 S$ and ND2 mitochondrial sequences were aligned using the MUSCLE algorithm (Edgar, 2004) in MEGA 6.0 (Tamura et al., 2013); SiaH and Rhod nuclear sequences were aligned using the online version of the automatic alignment software MAFFT 7 (Katoh and Standley, 2013; available at: http:// mafft.cbrc.jp/alignment/software), with the default options being applied. The phased haplotypes of the nuclear sequences were inferred by the Bayesian method implemented in PHASE 2.1 (Stephens and Donnelly, 2003), with the input files prepared with SEQPHASE (Flot, 2010; available online at: http://seqphase. mpg.de/seqphase/). We conducted the PHASE runs under default parameters (100 iterations with 100 burn-in and thinning 
interval of 10) and defined the minimum posterior probability of the haplotypes as 0.9 .

\section{Haplotype Networks, Genetic Structure, and Diversity}

Median-joining haplotype networks were constructed in POPART 1.7 (Bandelt et al., 1999; Leigh and Bryant, 2015). The species' genetic structure was first assessed with a Bayesian analysis of population structure (BAPS) to determine the most probable number of clusters $(k)$ in the dataset using BAPS 6.0 (Corander et al., 2008). We applied the "spatial clustering of individuals" option to the $16 \mathrm{~S}, \mathrm{ND} 2, \mathrm{SiaH}$, and Rhod datasets separately (as concatenating the fragments in mitochondrial versus nuclear datasets would reduce substantially the amount of information available for analyses, given most individuals had not all the four loci sequenced), allowing for a range of 1-30. The optimal $k$ values were defined based on the highest marginal loglikelihood estimates.

We also investigated the population structure and estimated the intra- and interpopulation diversity indices in ARLEQUIN 3.5 (Excoffier and Lischer, 2010). We calculated the genetic distances and $\Phi_{\text {ST }}$ values between populations, considering each sampling location as a population. The correlation between the genetic and geographical distances was evaluated using the Mantel test performed in ARLEQUIN 3.5. We also estimated the genetic differentiation among BAPS groups (see Results) and ran analyses of molecular variance (AMOVA, Excoffier et al., 1992) to infer the hierarchical organization of this structure. The haplotype $(\mathrm{h})$ and nucleotide $(\pi)$ diversities and the number of polymorphic sites $(S)$ were calculated for each location, BAPS group, and the total dataset.

\section{Phylogenetic Analyses and Molecular Dating}

We inferred the phylogenetic relationships among lineages and dated the main divergence events using a Bayesian multilocus species tree approach ( ${ }^{\star}$ BEAST; Heled and Drummond, 2010) in BEAST 1.8 (Drummond et al., 2012). We considered each BAPS group (northern, southern, and western groups, see Results) as a distinct lineage and pruned all loci datasets to one sequence per haplotype (i.e., excluding extra identical sequences) in each population. The trees were rooted with sequences from five outgroup species (Pithecopus azureus, P. hypochondrialis, P. ayeaye, Phyllomedusa tarsius, and Callimedusa tomopterna), and the nodes were calibrated using known $16 S$ and ND2 substitution rates $(0.28$ and $0.957 \%$ per million years, respectively), as proposed by Lemmon et al. (2007) and Crawford (2003).

The best models of nucleotide substitution were selected $a$ priori using the Akaike information criterion (AIC) in MEGA 6.0 (16S: GTR+G; ND2:TN93+G; SiaH: K2P+G+I and Rhod: $\mathrm{HKY}+\mathrm{G})$. We applied lognormal relaxed molecular clocks to the mitochondrial 16S and ND2 datasets but strict clocks to the SiaH and Rhod data, based on the striking low variability among these nuclear sequences (see Results) and the likelihood ratio tests also conducted in MEGA 6.0, which rejected the hypothesis of strict molecular clock only for $16 S$ and ND2 loci. We estimated the mean substitution rates for the nuclear genes and selected the Yule process as the tree prior for three independent runs of 500 million generations, with samples being taken every 5,000 generations. We checked for the convergence of the runs and for high effective sample sizes (ESS > 200) in TRACER 1.6 (available at: http://tree.bio.ed.ac.uk/software/tracer/) and combined the trees from the independent runs in LOGCOMBINER 1.8. The first 50,000 trees (10\%) of each run were discarded as burn-in, and the maximum clade credibility (MCC) of the species and independent gene trees were computed in TREEANNOTATOR 1.8. The trees were visualized in FIGTREE 1.4 (available at: http:// tree.bio.ed.ac.uk/software/figtree/).

\section{Demographic Patterns}

Signals of demographic events in the sampling locations, in the BAPS groups, and in the total dataset were investigated using neutrality tests $[D$ (Tajima, 1989) and $F s(F u, 1997)$ in ARLEQUIN 3.5, and R2 (Ramos-Onsins and Rozas, 2000) in DNASP 1.5 (Librado and Rozas, 2009)]. We also verified the distribution of pairwise differences in sequences in each BAPS group through mismatch distribution histograms (Rogers and Harpending, 1992; Harpending, 1994), obtained in ARLEQUIN 3.5.

We also ran the extended Bayesian skyline plot (EBSP, Heled and Drummond, 2008) analyses in BEAST 1.8 to infer changes in effective population size over time in each BAPS group (except for the western group, for which only a small number of sequences was available and the variability was low, see Results). We unlinked substitution, clock, and tree models for all the loci and specified a linear model of population size. We used the same clock models and substitution rates applied to the ${ }^{\star}$ BEAST analysis, and the operators and initial values for the mean population sizes were adjusted to improve the MCMC mixing, as recommended in the tutorial on the BEAST website (available at: http://beast.bio.ed.ac.uk/). We applied two independent runs of 500 million generations for each group (with samples taken every 5,000 generations). We used TRACER 1.6 to check the convergence and quality of the parameters and LOGCOMBINER 1.8 to combine the resulting trees. The final plots were based on the output files produced for the combined results.

\section{Ecological Niche Modeling (ENMs)}

We modeled the potential geographical distribution of P. nordestinus in present and past climate scenarios $[120 \mathrm{ka}$, Last Interglacial Maximum (LIG); 21 ka, Last Glacial Maximum (LGM); and 6 ka-mid-Holocene (HOL)] based on ecological niche modeling proceedings (ENMs). For this, we used all 78 current known occurrence points for the species encompassing our field collected sites for genetic population structure and other points available in two databases: SpeciesLink (http://splink.cria. org.br/) and Global Biodiversity Information Facility-GBIF (www.gbif.org). After, we filtered the occurrence points to obtain only single-cell occurrences when compared with cell resolution to models building $\left(4 \times 4 \mathrm{~km} \sim 16 \mathrm{~km}^{2}\right.$ cell size, in Equador region) (Table S2; Supporting information). 
We downloaded all 19 bioclimatic variables-of temporal scenario studied by us-that are available on the WorldClim Database (www.worldclim.org) and realized a factorial analysis according to Sobral-Souza et al. (2015) to select no-correlated variables using Caatinga/North Atlantic Forest biome delimitation as background. We used this background because it includes all occurrence points and encompass area for specie dispersion over time, two criteria for background selection proposed by Barve et al. (2011). Thus, we selected five variables, mean diurnal range (Bio 2), mean temperature of wettest quarter (Bio 8), mean temperature of driest quarter (Bio 9), annual precipitation (Bio 12), and precipitation of wettest mouth (Bio 13) (Table S3; Supporting information) to the model calibration. The models were built based on current climate condition and projected to midHolocene, LGM, and LIG climate using 2.5 arc-min resolution $\left(4 \times 4 \mathrm{~km}^{2}\right)$. The LIG paleoclimate condition data were proposed by Otto-Bliesner et al. (2006) using only CCSM3 simulation, and for this, here, we chose to use only this simulation for all paleoclimate scenario and leave out other AOGCMs simulations.

Several algorithms are able to infer species distribution (DinizFilho et al., 2009). Here, we applied five different algorithms based on different modeling techniques such as distance, envelope, and machine learning (based on absence and pseudo-absence) to infer Phitecopus nordestinus distribution. We used 1) Bioclim (Nix, 1986), 2) Mahalanobis distance (Farber and Kadmon, 2003), 3) domain (Gower distance; Carpenter et al., 1993), 4) support vector machines (SVM) (Tax and Duin, 2004), and 5) maximum entropy (Phillips and Dudik, 2008). To test the built models we subset the occurrences points into training and testing folding, with $75 \%$ as $25 \%$ of occurrences, respectively. We repeated this procedure 20 times to decrease the spatial collinearity between folding. In addition, we calculated the maximum sensitivity and specificity threshold (mms) and the true skill statistics (TSS) value for each repetition. According to Allouche et al. (2006), acceptable models present TSS values over 0.5 to cut each map and transform them on binary map. We used the mms value as threshold because it is the better threshold to use when only presence (distance and envelope) techniques are used in ENMs proceedings (Liu et al., 2016). After this, we used the ensemble approach (Araújo and New, 2007) to calculate the frequency of prediction by grid cell to create a consensus map for each algorithm. Finally, we concatenated all consensus maps and then obtain a consensus map for each temporal climatic scenario (Figure 1).

\section{Model Testing With Approximate Bayesian Computation}

Based on our phylogenetic and ecological inferences, we designed two biogeographic scenarios to explain the geographical genetic structure detected in the preceding analyses to test the models in an approximate Bayesian computation ( $\mathrm{ABC}$ ) framework. In scenario 1 (models 1-3; Figure 2A), the divergence between the northern and southern $P$. nordestinus populations is related to the relocation of the São Francisco River during the PlioPleistocene, with three models: 1 -simple vicariance among the northern, southern, and western populations; 2-divergence between northern and southern populations coinciding with the relocation of the São Francisco River, followed by the colonization of the western population by individuals from the southern population; and 3-divergence of the northern and southern populations by the São Francisco River, followed by the colonization of the western population by individuals from the northern population. In scenario 2 (models 4-6; Figure 2B), the diversification observed in $P$. nordestinus is derived from the last glacial cycle: 4 -a single refugia during the LIG as seen in the ENM (Figure 1E) with posterior colonization of both northern and western populations; 5-two distinct refugia, corresponding to the northern and southern populations, followed by the colonization of the western population by individuals from the southern population; and 6-two distinct refugia, corresponding to the northern and southern populations, followed by the colonization of the western population by individuals from the northern population. In scenario 2 , after the period of refugia during the LGM, we set populations to increase in number, represented by exponential growth. We first compared the models within scenarios and then compared the best model from each scenario to select the best overall hypothesis.

We developed custom $\mathrm{R}$ scripts to simulate data under each model using $m s$ (Hudson, 2002). The simulations were conducted using the same loci length and sample sizes of the empirical data and set independently for each dataset, as concatenating mitochondrial versus nuclear sequences would considerably reduce the number of individuals available for analysis (since most of them had not all the regions sequenced); nevertheless, the summary statistics computed for all markers were considered jointly in the model choice. We estimated a unique prior interval for the effective population size $\left(N_{\mathrm{e}}\right)$ and then used this parameter to delimit appropriate prior distributions for each $\theta$ (theta), considering $\theta_{\text {mit }}=N_{\mathrm{e}} \mu$ and $\theta_{\text {nuc }}=4 N_{\mathrm{e}} \mu$. The mutation rates (per site per generation) for each region and the divergence times' intervals were given by uniform distributions delimited by prior information obtained from ${ }^{*} \mathrm{BEAST}$ results. In scenario 1 , the first divergence event encompasses the Plio-Pleistocene (5.33 to 0.12 Mya), while in scenario 2 it corresponds to the period from the LGM to the present time [values transformed in coalescent units (number of generations $/ 4 N_{\mathrm{e}}$ )]. The other parameters (number of individuals after a bottleneck event and growth rates) also followed uniform prior distributions (see more details in Table S4; Supporting information). The R scripts used are available on GitHub (https://github.com/luizbartoleti/Pnordestinus).

We first performed a round of 100,000 preliminary simulations per model with flat distributions of the parameters (Table S4; Supporting information). Based on these simulated data, we calculated summary statistics - total nucleotide diversity $(\pi)$, number of segregating sites (ss), Tajima's D (D), nucleotide diversity within $(\pi \mathrm{w})$, and between $(\pi \mathrm{b})$ populations-using a PERL script written by N. Takebayashi (available at http:// raven.wrrb.uaf.edu/ ntakebay/teaching/programming/coalsim/ scripts/msSS.pl) and grouped them in vectors (2-5 statistics per vector) to find the combination that would optimize our model selection, i.e., which vector more accurately identifies the best model given the simulated data. This step was included because, while using few statistics could be less informative, including an 


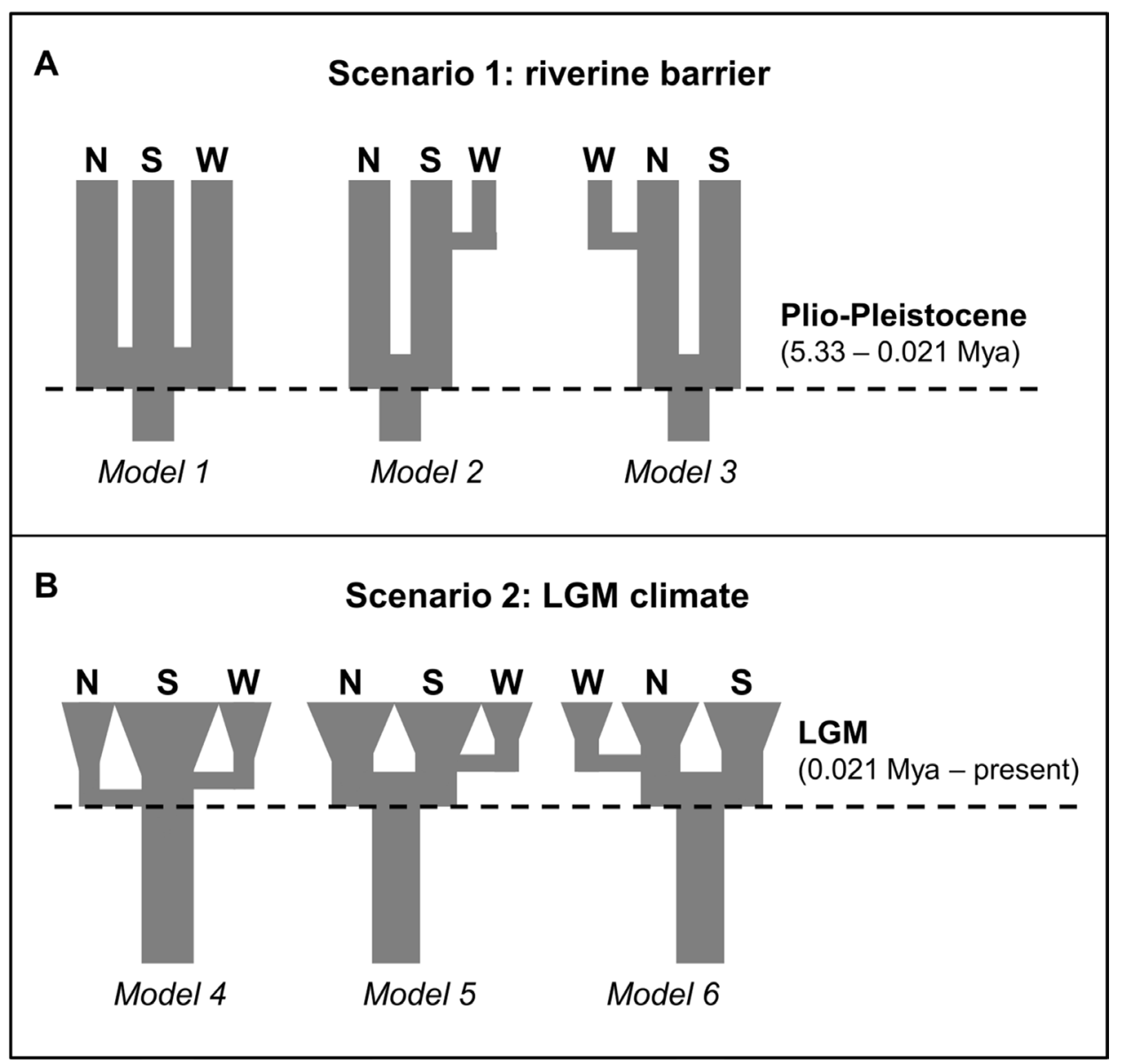

FIGURE 2 | Alternative scenarios for diversification of the $P$. nordestinus populations of the South, North, and West lineages tested with multilocus approximate Bayesian computation (ABC). (A) Scenario 1 (models 1-3), the divergence between the Northern and Southern P. nordestinus populations is related to the relocation of the São Francisco River (SFR) during the Plio-Pleistocene and alternative three models. (B) Scenario 2 (models 4-6), the diversification observed in P. nordestinus is derived from the last glacial cycle as seen modeling in the ENM analysis (see Figure 1) (Pleistocene Refuges Hypothesis). See Material and Methods for more detail.

excessive amount of values may provide not additional useful information for the estimation process and introduce stochastic noise. We performed a regression step with 10 simulations for each model and used them as PODs (pseudo-observed data). The best vector of summary statistics would enhance the probability of choosing the true model over the average probability of choosing any other model (Tsai and Carstens, 2013). We then conducted a parameter restriction to narrow their prior distributions and get a more reliable model choice. We used the "abc" package for $\mathrm{R}$, version 1.4 (Csilléry et al., 2012) and applied a threshold of $1 \%$ of the simulations more similar to our empirical data based on a neural network rejection.

With the parameters restricted and the best vector of summary statistics (ss, D, and $\pi \mathrm{b}$ ), we then performed more 300,000 simulations per model. Model selection was also made using the "abc" package and a threshold of $1 \%$ of the simulations. We calculated the posterior probabilities of the competing models to find the best model within each scenario and then compared these two models to find the best overall model. To investigate the robustness of our model choice, we performed a cross-validation analysis using 100 random simulated summary statistics as PODs to test if the models that we built were significantly different from each other (excluding the possibility of a random model selection). Finally, we evaluated the goodness-of-fit of the most probable model by comparing the statistics calculated from the retained simulations to our empirical data based on a principal component analysis (PCA), also with "abc" package in R.

\section{RESULTS}

\section{General Aspects of the Data}

We obtained 151 sequences of $16 S$ gene (1035 base pairs or bps), 168 sequences of the ND2 (813 bps), 155 sequences of SiaH (361 bps), and 189 of the Rhod locus (378 bps). All the reconstructed phased haplotypes had posterior probabilities higher than 0.9 , which resulted in 310 phased $\mathrm{SiaH}$ sequences and 378 phased Rhod sequences. 


\section{Phylogenetic Inferences, Haplotype Networks, Genetic Structure, and Diversity}

The mitochondrial networks showed three major haplogroups separated by a large number of mutational steps, which correspond to distinct geographic regions (Figures $\mathbf{3 A}-\mathbf{C}$ ), but a less clear subdivision was found in the nuclear genes (Figures 3D, E). The lineage divergences based in the Bayesian phylogenetic inferences corroborate the haplotype networks and geographical structure (Figure 4). The mitochondrial gene ( $16 S$ and ND2, Figures 4A, B, respectively) showed similar topologies and recovered the three major geographically structured $P$. nordestinus clades: the first includes specimens distributed on the north of SFR (Rio Grande do Norte, Ceará, Paraíba, Pernambuco, and Alagoas states, hereafter referred to Northern group); the second is composed by few haplotypes from western Bahia (Catieté and Aurelino Leal populations, hereafter referred to Western group); and a third clade genetically more distant from the other two that includes individuals collected in Sergipe and remaining localities in Bahia states, all distributed in South of the SFR (hereafter referred to Southern group). Nuclear gene trees, however, exhibited lower resolution in the internal nodes (Figures $4 \mathrm{C}, \mathrm{D}$ ), and two main mito-nuclear discordances in our topologies were detected: i) few specimens from Areia Branca and Laranjeiras, both located in Sergipe state (Southern group), were nested with Northern group (see SIAH tree-Figure 3C); and ii) Western group varied among nuclear markers, grouping with Northern group in Rhod tree and with Southern group in SIAH topology (Figure 4).

The BAPS results indicated an optimal partition of $k=3$ for both $16 S$ and ND2 datasets, as observed in the other analyses (see also Figure $\mathbf{S 1}$ in supporting information). For the nuclear SiaH sequences, the analyses indicated an optimal subdivision of two groups $(k=2)$, mostly corresponding to the two margins of the SFR, and no partitioning $(k=1)$ in the case of the Rhod dataset (Figure 1, Figure S1). The only locality with samples assigned

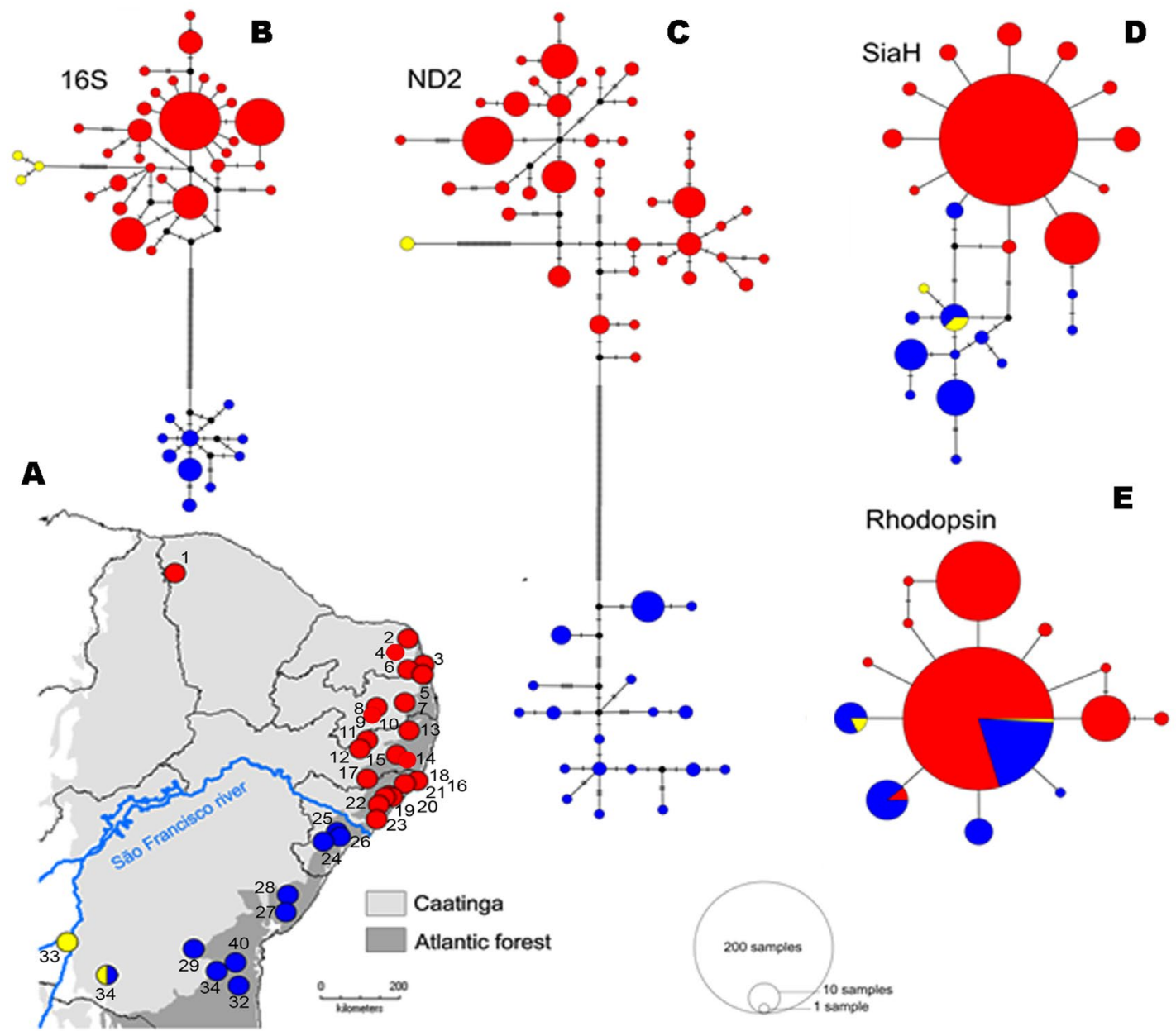

FIGURE 3 | Spatial distribution (A) and haplotypes genealogies for Median-joining analysis of $16 S$ (B), ND2 (C), SiaH (D), and Rhod (E) fragment genes recovered of the $P$. nordestinus dataset. Each haplotype is represented by a circle whose area is proportional to its frequency (see legends). Samples are colored according to the haploclades recovered in the Bayesian topology and Bayesian analysis of population structure (BAPS) analysis. Red represent the Northern group, blue represent the Southern group, and yellow represent the West group. Note the blue and red lineages of the P. nordestinus bisected by current course of the SFR (light blue dashed). The numbers correspond to the localities named in BAPS analysis (Supporting information - Figure S1). 


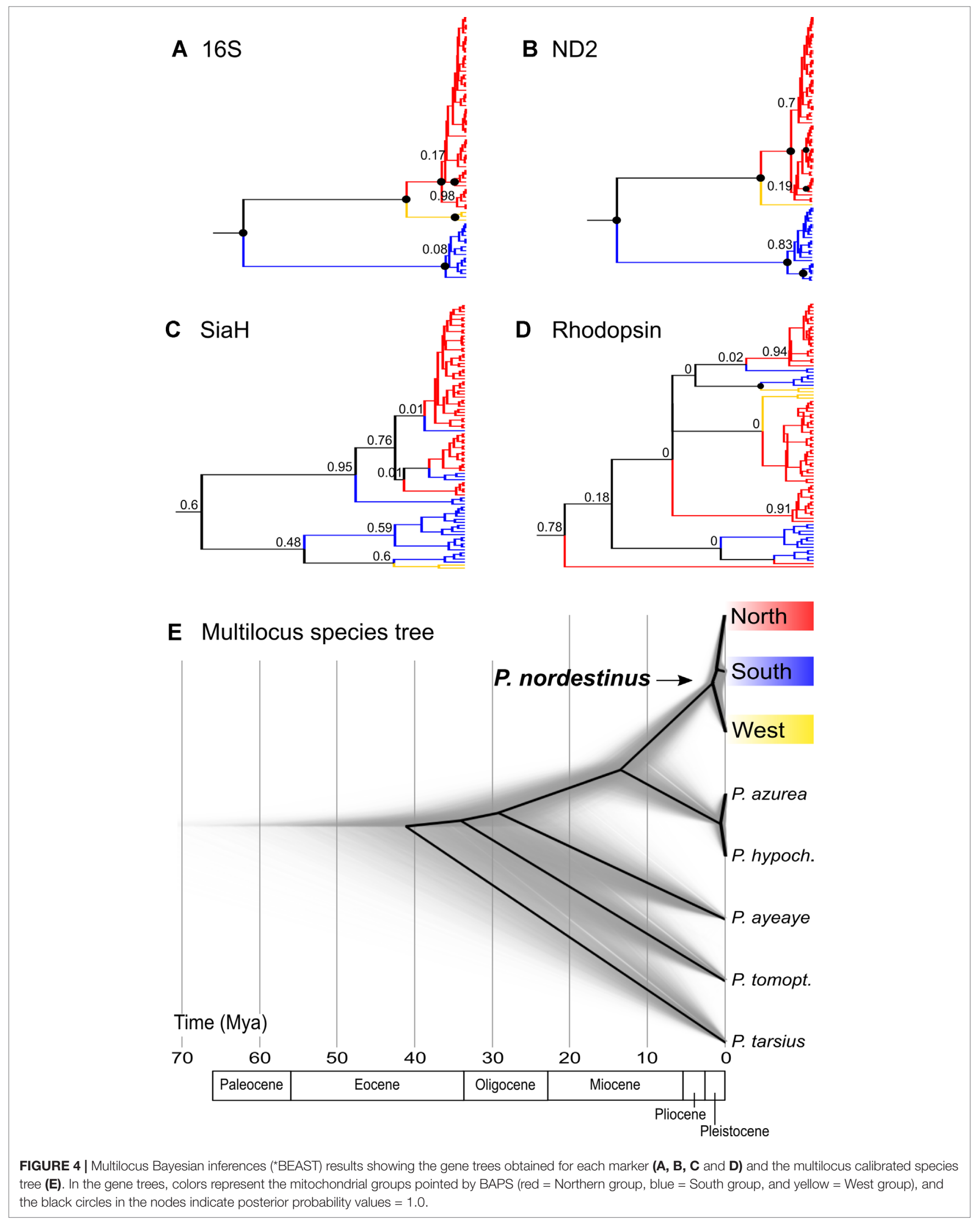


to different groups was Caetité, in western Bahia (Supplemental Figure S1), whereas in $16 S$ and ND2 tree, it was nested with the northern group; in SiaH and Rhod, this sample was nested with the southern group.

The significant $\Phi_{\text {ST }}$ values between locations from different BAPS groups (excluding the estimates for Caetité vs. other populations since this location contains individuals grouped in different genetic clusters) were consistently higher and varied from 0.94 to 1 (for $16 S$ ), 0.42 to 1 (ND2), 0.42 to 1 (SiaH), and 0.12 to 0.44 (Rhod) (Support information-Tables S4-S7). Most pairwise $\Phi_{\text {ST }}$ values between populations grouped in the same BAPS cluster were nonsignificant, being the significant estimates usually higher among northern populations and varying from 0.12 to 1 (16S), 0.08 to 1 (ND2), 0.03 to 0.54 (SiaH), and 0.08 to 0.37 (Rhod) (Tables S5-S8). The genetic distances were also generally smaller between locations of the same group for all loci (Support information's-Tables S9-S12). The Mantel tests indicated significant correlations between geographical and $\Phi_{\mathrm{ST}} /$ genetic distances when the total datasets were analyzed, but no evidence of isolation by distance was detected when each BAPS group was analyzed separately (data not shown).

The AMOVA indicated that most of the genetic variance arises among the Northern, Southern, and Western groups for the $16 \mathrm{~S}$ (94.9\%), ND2 (92.9\%), and SiaH (81.9\%) datasets but not for the Rhod sequences $\left(17.7 \%\right.$, Table 1). The pairwise $\Phi_{\text {ST }}$ values were also high for all markers except Rhod (Table 2), and the corrected genetic distances varied from 12.3 to 61.6 pairwise differences for the $16 \mathrm{~S}$ sequences, 23.9 to 87.0 for ND2, 0.8 to 4.0 for $\mathrm{SiaH}$, and 0.1 to 0.2 for Rhod (Table 3 ).

TABLE 1 | Analysis of molecular variance (AMOVA) for the mitochondrial and nuclear dataset of the $P$. nordestinus populations. The hierarchical tests were designed considering BAPS groups.

\begin{tabular}{llc}
\hline Region & Source of variation & Variation percentage \\
\hline $\mathbf{1 6 S}$ & Among groups & 94.89 \\
& Within groups & 5.11 \\
$\mathbf{N D 2}$ & Among groups & 92.95 \\
& Within groups & 7.05 \\
$\mathbf{S i a H}$ & Among groups & 81.89 \\
& Within groups & 18.11 \\
$\mathbf{R h o d}$ & Among groups & 17.71 \\
& Within groups & 82.29
\end{tabular}

TABLE 2 | Pairwise $\Phi_{\mathrm{ST}}$ values between north, south, and west groups recovered in BAPS analysis of the $P$. nordestinus populations. In bold, the statistical significant results.

\begin{tabular}{llll}
\hline Region & & North & South \\
\hline $\mathbf{1 6 S}$ & South & 0.954 & \\
\multirow{2}{*}{ ND2 } & West & 0.809 & 0.948 \\
& South & 0.932 & \\
SiaH & West & 0.808 & 0.905 \\
\multirow{2}{*}{ Rhod } & South & 0.818 & \\
& West & 0.899 & 0.166 \\
& South & 0.172 & \\
& West & 0.289 & 0.130
\end{tabular}

TABLE 3 | Genetic distances between north, south, and west groups of the $P$. nordestinus.

\begin{tabular}{llccc}
\hline Region & & North & South & West \\
\hline $\mathbf{1 6 S}$ & North & 2.885 & 64.617 & 14.457 \\
& South & 61.379 & 3.591 & 64.035 \\
\multirow{2}{*}{ ND2 } & West & 12.348 & 61.573 & 1.333 \\
& North & 5.410 & 91.573 & 26.618 \\
& South & 84.293 & 9.151 & 91.543 \\
SiaH & West & 23.914 & 86.967 & 0.000 \\
& North & 0.448 & 5.032 & 2.337 \\
& South & 3.476 & 2.663 & 2.337 \\
Rhod & West & 3.999 & 0.756 & 0.500 \\
& North & 0.603 & 0.799 & 0.873 \\
& South & 0.130 & 0.733 & 0.817 \\
& West & 0.238 & 0.117 & 0.667 \\
\hline
\end{tabular}

Above the diagonals, the average number of sequences' pairwise differences between groups $(D)$; below the diagonals, the corrected average number of pairwise differences (DA). In gray, the average number of differences within each group.

The total and within-group haplotype and nucleotide diversities were higher for the mitochondrial datasets (Table 4). The variability of the southern group was slightly higher for all markers, and the pattern within sites varied considerably, due in part to the reduced sample sizes (Table 4, Support informationTable S13).

\section{Divergence Time Estimation}

The ${ }^{\star} \mathrm{BEAST}$ analysis indicated that $P$. nordestinus diverged from the outgroup at ca. 13.24 Mya (95\% HPD $=8-19$ Mya: Figure 4E). The intraspecific lineages' divergences started at ca. 1.57 Mya (95\% HPD = 0.84-2.61 Mya); however, the phylogenetic relationships among the three lineages were not clearly resolved, given that the divergence time' intervals overlap, and the posterior probability of the north-south clade is low ( $\mathrm{PP}=0.6$, Figure $4 \mathrm{E})$.

The trees for the mitochondrial genes presented highly congruent topologies, indicating that the southern group lineage split off first [16S: 9.99 Mya (95\% HPD = 6.1-14.16); ND2: 8.75 Mya (95\% HPD = 5.23-12.78)], while the northern and western samples were more closely related and diverged only more recently [16S: 2.68 Mya (95\% HPD = 1.58-4.03); ND2: 2.3 Mya $(95 \%$ $\mathrm{HPD}=1.38-3.73$ ), Figure 4; Supporting information Figure 2]. The SiaH gene tree presented a less marked differentiation among the three lineages, and, in contrast with the mitochondrial trees, the western samples were more closely related to the southern group; however, most of the nodes have low statistical support (Figure 4C). The Rhod tree exhibited almost no structuring of the groups and nodes' posterior probabilities even lower (Figure 4D; Supporting information).

\section{Demographic Patterns}

All the neutrality tests revealed signs of demographic expansion (evidenced by the negative value in $D$ and $F$ s tests, and low values in $R 2$ test) in the northern group, based on the mitochondrial markers, a pattern also detected in the $D$ and Fs tests for SiaH sequences (Table 4). In the southern group, only $R 2$ test on the $16 S$ sequences indicated population expansion, and none of the 
TABLE 4 | Diversity indices and neutrality tests' result for each BAPS group and for the total datasets of $P$. nordestinus.

\begin{tabular}{|c|c|c|c|c|c|c|c|c|}
\hline & $\mathbf{N}$ & $\mathbf{h}$ & $\mathbf{s}$ & Hd (s.d). & $\pi(s . d)$ & $D$ & Fs & $R 2$ \\
\hline \multicolumn{9}{|l|}{$16 S$} \\
\hline North & 129 & 31 & 37 & $0.86(0.02)$ & $0.003(0.002)$ & $-1.80\left(^{*}\right)$ & $-18.50\left(^{* \star}\right)$ & $0.04\left(^{*}\right)$ \\
\hline South & 19 & 10 & 21 & $0.88(0.06)$ & $0.003(0.002)$ & -1.46 & -2.24 & $0.08\left(^{* *}\right)$ \\
\hline West & 3 & 3 & 2 & $1(0.27)$ & $0.001(0.001)$ & 0.00 & -1.22 & 0.24 \\
\hline Total & 151 & 44 & 107 & $0.89(0.02)$ & $0.017(0.008)$ & -0.43 & -1.42 & 0.07 \\
\hline \multicolumn{9}{|l|}{ ND2 } \\
\hline North & 131 & 40 & 54 & $0.93(0.01)$ & $0.007(0.003)$ & $-1.41\left(^{*}\right)$ & $-17.59\left(^{* \star}\right)$ & $0.05\left(^{*}\right)$ \\
\hline South & 35 & 21 & 44 & $0.9(0.04)$ & $0.011(0.006)$ & -0.52 & -4.06 & 0.09 \\
\hline West & 2 & 1 & 0 & $0(0)$ & $0(0)$ & 0.00 & 0.00 & 0.00 \\
\hline Total & 168 & 62 & 167 & $0.95(0.01)$ & $0.042(0.021)$ & 0.57 & 0.00 & 0.10 \\
\hline \multicolumn{9}{|l|}{$\mathrm{SiaH}$} \\
\hline North & 260 & 12 & 11 & $0.41(0.04)$ & $0.001(0.001)$ & $-1.74(* *)$ & $-10.66\left(^{* \star}\right)$ & 0.02 \\
\hline South & 46 & 14 & 9 & $0.83(0.04)$ & $0.007(0.004)$ & 0.85 & -4.23 & 0.15 \\
\hline West & 4 & 2 & 1 & $0.5(0.26)$ & $0.001(0.002)$ & -0.61 & 0.17 & 0.43 \\
\hline Total & 310 & 25 & 19 & $0.57(0.03)$ & 0.005 (0.003) & -1.08 & $-13.47\left(^{\star \star}\right)$ & 0.04 \\
\hline \multicolumn{9}{|l|}{ Rhod } \\
\hline North & 292 & 10 & 7 & $0.53(0.03)$ & 0.002 (0.002) & -0.94 & -5.28 & 0.04 \\
\hline South & 82 & 5 & 4 & $0.61(0.05)$ & $0.003(0.002)$ & -0.18 & -0.55 & 0.09 \\
\hline West & 4 & 2 & 1 & $0.67(0.2)$ & $0.002(0.003)$ & 1.63 & 0.54 & 0.33 \\
\hline Total & 378 & 13 & 10 & $0.57(0.03)$ & $0.002(0.002)$ & -1.21 & $-7.90\left(^{\star \star}\right)$ & 0.03 \\
\hline
\end{tabular}

$N$, number of sequences; $h$, number of haplotypes; S, number of segregating sites; Hd, haplotype diversity; $\pi$, nucleotide diversity; s.d., standard deviation; D, Tajima's D; Fs, Fu's Fs; R2, Rozas and Ramos-Onsis' R2. In bold, the statistical significant values for the neutrality tests $\left({ }^{*} p<0.05,{ }^{* *} p<0.02\right)$.

results were significant for the western group, probably due to its smaller sample size (Table 4). Few significant results were found within geographical locations, except for some northern populations (despite the fact that they were not totally congruent among markers and tests Table S14). For the complete datasets, only the SiaH and Rhod sequences presented significant $F$ s values (Table 4). The EBSP analyses indicated population growth in both northern and western groups, starting at ca. 0.5 Mya (Figure 5).

\section{Ecological Niche Models}

The ENMs suggested a robust geographical expansion during LIG to current climate conditions (Figure 1). During LIG, the only high suitability area was located in southern region of São Francisco River (Figure 1E), suggesting an influence of São Francisco Riverine Basin on species distribution. Between LIG to LGM climate conditions, a marked geographical expansion occurred in the southern-northern direction with expansion to western region (Figure 1D, E). After LGM, the geographical distribution has remained stable (Figures 1B-D).

\section{Model Testing With Approximate Bayesian Computation}

The best supported model was model 2 (Table 5): an ancient split between the northern and southern populations resulting from the relocation of the SFR, with posterior founding of the western region by individuals from the southern populations. This analysis had a high Bayes factor (BF > 400), which strongly supports the conclusion that the diversification of the population was due to the relocation of the river (Table 5).

The confusion matrix generated by the cross-validation (Supplemental Figure S3, Table S15) indicated that the PODs matched satisfactorily the models under which they were generated, and the correct models were always more frequently recovered (except for model 5 evaluation, which indicated model 6 as the correct model with a slightly higher frequency). The analysis showed a clear discrimination between simulations from different scenarios; the higher number of erroneously recovered models in the same scenario, though, indicates that withinscenario demographic inferences should be taken cautiously and further explored in following studies. The goodness-of-fit PCA analysis confirmed that the summary statistics simulated under model 2 are considerably similar to our empirical values (Figure S4, Supporting information).

\section{DISCUSSION}

\section{Strong Phylogeographic Break in $P$. nordestinus}

The present study included a broader sample of populations from the geographic range of $P$. nordestinus, permitting a better resolution of the sources of the genetic variation reported by Faivovich et al. (2010). Our results indicated that $P$. nordestinus is composed of distinct geographically structured lineages, which probably diverged due to geological processes involved in the translocation of São Francisco river.

The major phylogeographical break was detected between the populations located at the north versus south of SFR (Figures 3, 4, Tables 1-3 and 5). The divergence between these lineages was profound [ca. 1.5 Mya (0.8-2.6 Mya); see Results] and consistent with the presence of such topographic barrier, dated to Early-to-Mid Cretaceous (Potter, 1997). As expected under the Riverine Barrier hypothesis' predictions, this barrier would reduce gene flow between populations in opposite riverbanks over time, resulting in greater genetic differentiation 


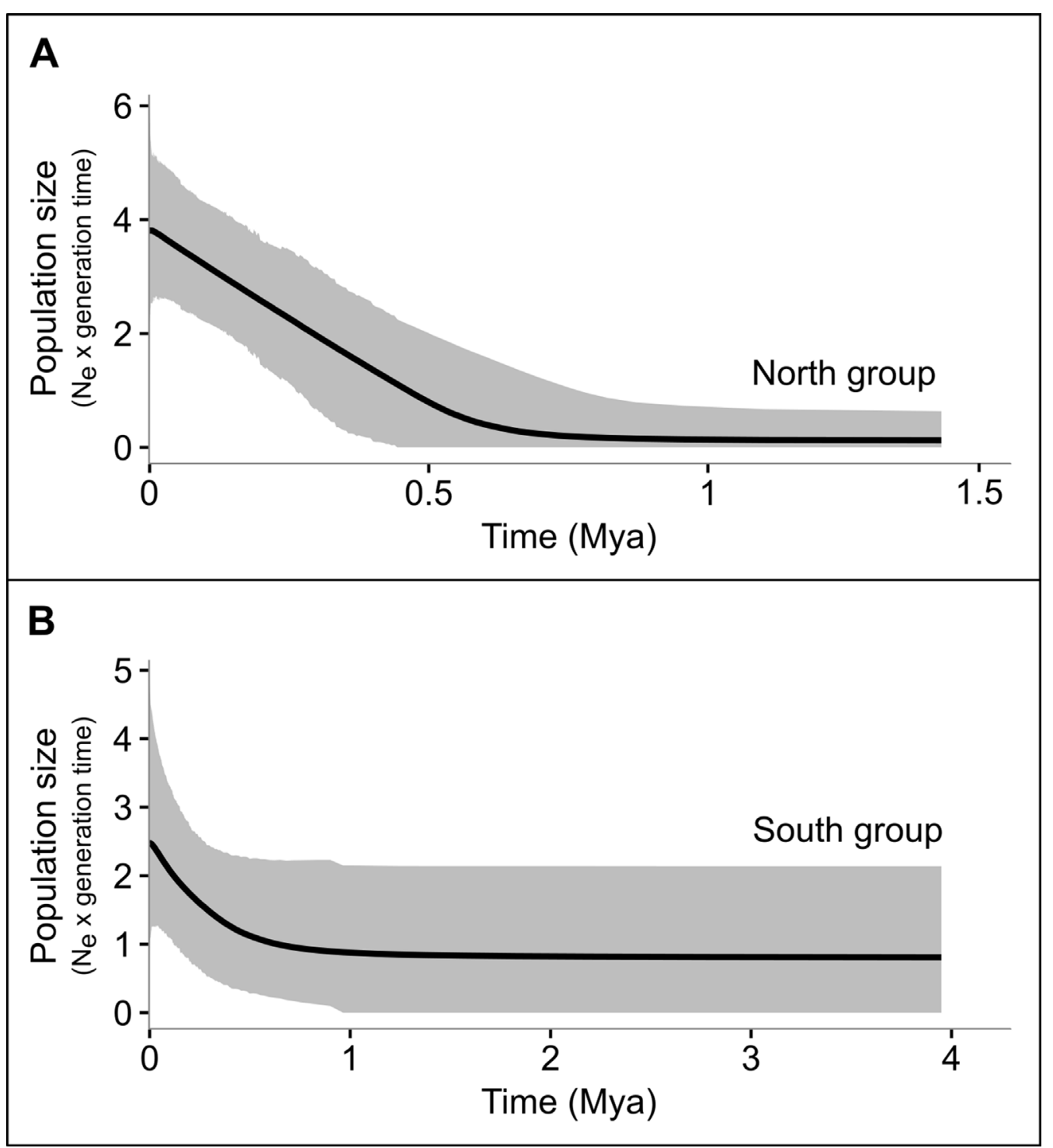

FIGURE 5 | Multilocus extended Bayesian skyline plots (EBSP) illustrating effective population sizes (Ne $\times$ generation) though time (in Mya) of the north (A) and South (B) groups of $P$. nordestinus. Gray shades represent the $95 \%$ higher posterior density intervals.

TABLE 5 | Results of the ABC model selection assuming two major scenarios for diversification in $P$. nordestinus lineages (Riverine barrier versus Climate refugiaFigure 2).

\begin{tabular}{lcccc}
\hline Scenario & mODEL & $\begin{array}{c}\text { Within } \\
\text { scenarios }\end{array}$ & $\begin{array}{c}\text { AMONG } \\
\text { SCENARIOS }\end{array}$ & $\begin{array}{c}\text { BAYES } \\
\text { FACTOR }\end{array}$ \\
\hline $\mathbf{1}$ & 1 & 0.2729 & - & \\
Riverine & 2 & $\mathbf{0 . 6 4 8 7}$ & $\mathbf{0 . 9 9 7 6}$ & 411.0854 \\
barrier & 3 & 0.0785 & - & \\
$\mathbf{2}$ & 4 & 0.1782 & - & \\
Climate & 5 & $\mathbf{0 . 6 1 3 6}$ & 0.0024 & \\
refugia & 6 & 0.2082 & - & \\
\hline
\end{tabular}

The best model in each scenario (the one with the highest posterior probability - in bold) were used to perform the analysis among scenarios, which ultimately selected the best-fitting model for our data. in comparison with that found among populations on the same margin (Rull, 2011). Our ABC model testing also recovered strong probabilistic support for this scenario, confirming the riverine barrier hypothesis as the most plausible vicariance event for $P$. nordestinus. The SFR has long been considered an important geographic barrier in the Atlantic Forest biome, which has influenced vicariant processes at both intergeneric (Rodrigues, 1996; Rodrigues and Juncá, 2006; Siedchlag et al., 2010) and intraspecific levels (Pelegrino et al., 2005; Passoni et al., 2008; Siedchlag et al., 2010; Nascimento et al., 2011; Werneck et al., 2012; Nascimento et al., 2013). The diversification time estimates to lineages of the rodents (Nascimento et al., 2013) and dipterans (Coutinho-Abreu et al., 2008), lizards (Werneck et al., 2015) from opposite SFR banks 
during Plio-Pleistocene transition, time frame coincident with North and South split detected in P. nordestinus.

During the Plio-Pleistocene transition, the uplifting of the Parnaíba River basin resulted in a shift in São Francisco River drainage, which followed a transversal geological fault on the northeastern coast of Brazil (King, 1956; Mabesoone, 1994). The split of the northern and southern groups of P. nordestinus was also dated to this period; this geomorphological event had a profound effect on the local biodiversity: examples of allopatric speciation and lineages' differentiation in this region include lizards of the genera Eurolophosaurus (Passoni et al., 2008), Calyptommatus (Schidchlag et al., 2011) and Phyllopezus (Werneck et al., 2012), and the Caatinga species complex Tropidurus semeitaeniatus (Werneck et al., 2015); rodents of the genus Calomys (Nascimento et al., 2011); and dipterans of the genus Lutzomyia (Coutinho-Abreu et al., 2008).

While landscape changes, such as shifts in the drainage of major rivers, have played a clear role in the differentiation of lineages, subsequent during this historical process, intermediate paleodrainage phases would have occurred, as indicated by debris flows and fluvial deposits dated to the Pleistocene (Lima et al., 2014). These events promoting micro-climatic alterations that demanded differential ecological responses in different taxa. This reinforces the role of the continuous landscape changes during the Pleistocene in the region of São Francisco river (Lima et al., 2014) in shaping the current genetic diversity and structure of the populations. Thus, both ancient geographic barriers and Pleistocene climate changes could have contributed to the patterns observed, and discriminating which event was more relevant for $P$. nordestinus history is not a simple task. Given their overlapping time frame, the genomic signatures of these two processes might be confounded or even cancelled out (Mona et al., 2014; Thomé et al., 2014). In addition, the dispersal abilities and generation time of each species should be considered to evaluate the role of the climatic changes as source of the molecular diversity of species, as validated by Arenas et al. (2014).

We also recovered two areas of predicted stability (refugia) during the period of the LGM, as pointed by our niche models (Figure 1). These areas are separated by the São Francisco River and coincide with the Pernambuco and Bahia centers of endemism proposed by Carnaval and Moritz (2008), which presumably promoted the divergence patterns in several organisms (Carnaval et al., 2009; Menezes et al., 2016). However, our molecular dating indicated that the divergence between northern versus southern $P$. nordestinus groups occurred in the Plio-Pleistocene period; thus, our results suggest that the Pleistocene refugia would have reinforced rather than originate the geographic patterns found in our dataset. We should also consider that we inferred the effects of climate condition based on paleo-simulation of the last $120 \mathrm{kya}$ (LIG), but distinct proxies indicate that the multiple cycles of Quaternary glaciations have presented equivalent climatic oscillations over at least the last $800 \mathrm{ka}$ (see Lisieck and Raymo, 2005). Thus, the climate changes that occurred in Plio-Pleistocene, when São Francisco River Basin was modified, can also support the genetic pattern showed here. Therefore, SFR course modification and climate change associated to Plio/Pleistocene period (5 to $1.5 \mathrm{Ma}$ ) may, together, explain $P$. nordestinus diversification better than the hypothesis of LGM climate change.
Ours results also detected signals of demographic expansion for both the northern and southern groups of $P$. nordestinus, which partially violates the predictions of the riverine barrier hypothesis (Moritz et al., 2000). However, the EBP analyses showed that population growth in both lineages started at ca. 0.5 Mya, which suggest that Pleistocene climatic shifts possibly have induced such demographic changes after the lineages split. Demographic oscillations are expected in forest-dwelling species affected by Pleistocene climatic shifts in the Atlantic Forest (Carnaval et al., 2009; Batalha-Filho et al., 2012; Dantas et al., 2014), which would be reflected in low genetic diversity, and a strong signal of recent population expansion. This signature was observed mainly in $P$. nordestinus northern populations, as we detected significant negative results of Tajima's D, Fu and Li's statistic, and R2 tests. According to EMN predictions, $P$. nordestinus northern group may have been isolated within the Pernambuco refugia (Carnaval and Moritz, 2008) during the LGM, which left a footprint in the genome of these populations. In the southern group, by contrast, our demographic tests detected a major signal of expansion only in the $16 \mathrm{~S}$ marker ( $R 2$ test). Although the Bahia refugia (Carnaval and Moritz, 2008), the largest center of endemism of the Atlantic Forest, is located in the central portion of the biome, we sampled only few sites in this region; thus, the weaker signs of historical demographic processes in these populations might be a result of our lower sampling.

\section{Incongruence Between Markers and Secondary Contact Among Evolutionary Lineages}

We obtained few conflicting results for the mitochondrial and nuclear markers (gene trees, BAPS, and network genealogy) with respect to specimens from Areia Branca and Laranjeiras (hereafter referred to an ABL group), both located in the Sergipe state, which are located on the southern margin of the São Francisco River. These samples were grouped with the northern clade in the SiaH and Rhod fragment analyses, whereas mitochondrial markers (16S and ND2) was nested in the southern clade. This incongruence is expected in recently diverged lineages (and often causes noise in biogeographic studies; see review of the Toews and Brelsford, 2012) and may be a result of incomplete lineage sorting or mitochondrial introgression resulting from secondary contact between evolutionary lineages. In fact, the longer coalescence time of the nuclear markers in comparison with those of the mitochondrial genome implies that lineage sorting is more easily detected in the mitochondrial markers. While this can be ruled out in some cases, if the sorting of lineages is the source of the disagreement between the mitochondrial and nuclear signals, we would not expect any biogeographic pattern in the nuclear topology to affect populations that present well-defined structure in the mitochondrial trees (Funk and Omland, 2003). In the case of the ABL group, in fact, the mitochondrial sequences were highly divergent in comparison with the northern margin, even though these localities grouped with the northern clade in the analysis of the SIAH sequence. In this case, incomplete lineage sorting may be related to the formation of intermediate paleo-drainage basins during the Pleistocene, as indicated by the presence of debris flows and fluvial deposits (Lima et al., 2014) dated to ca. $450 \mathrm{ka}$, indicating that the course of the lower São Francisco River ran to the 
south of its present position. In this historical configuration, Areia Branca and Laranjeiras, which are located south of the current SFR curse, would have grouped with the northern populations, and this was confirmed by the nuclear markers, reflecting lower mutation rates, recombination effects, and higher effective population size in comparison with the mitochondrial genome, which may represent a more recent separation. A similar pattern of landscape restructuring may account for the sharing of haplotypes between lizard populations of the same region that are currently isolated by the São Francisco River (Werneck et al., 2015).

Alternatively, sex-biased dispersal may explain the incongruence detected between mitochondrial and nuclear markers in the regional scale. When individuals of one sex showed dispersal or phylopatric behavior, the signature of the genetic differentiation between populations could be recovered when estimate using uni- and biparental markers (Prugnolle and Meeus, 2002; Liebgold et al., 2011). Unfortunately, due to the few female samples, we cannot verify the sex-biased behavior signal as the source of this incongruence. To validate these hypotheses to require combine observational data of the mating system and adequate female sampling, future studies specifically designed will be beneficial to explain this incongruence.

\section{Incomplete Lineage Sorting or Secondary Contact Among Evolutionary Lineages?}

The evolutionary history of the Western $P$. nordestinus populations requires more detailed analyses. While the mitochondrial markers indicated a link with the northern group, the nuclear markers grouped these sequences with either the southern $(\mathrm{SiaH})$ or northern (Rhod) groups. Our ABC framework suggested that the western region was recently (post-LGM) colonized by individuals from the southern population after the main northern-southern split. This prediction is consistent with the signal of population expansion found in the southern group (16S fragment), even though no evidence of demographic change was found in the western clade (possibly due to the small sample size). Expansion after the vicariant event would coincide with the warmer climate following the glaciations of the Pleistocene and may account for the colonization of the western area.

P. nordestinus is a lowland species distributed throughout much of northeastern Brazil in areas of Caatinga or associated habitats of the Atlantic Forest and Cerrado morphoclimatic domain (Caramaschi, 2006; Faivovich et al., 2010). This species is normally found near water bodies in open areas with predominantly herbaceous vegetation. Caldas et al. (2014) reported that populations in Caatinga and Atlantic Forest habitats occupy similar microhabitats and use similar spatial resources, which may reflect a degree of niche conservation, even though body sizes vary between these biomes. The historical transition of ancient populations between these regions would thus be a plausible explanation for the colonization of the western populations. In this case, we have interpreted the disagreement between the mitochondrial and nuclear datasets as the retention of ancestral polymorphism through incomplete lineage sorting. Nevertheless, we agree that the short divergence time between the southern and western populations and the sharing of a number of haplotypes with the northern populations may require the testing of a more comprehensive hypothesis to account for these disagreements. Even so, possible gene flow between southern and northern populations within a putative secondary contact zone might also have created cytonuclear noise in the phylogenetic inferences due to introgression (Toews and Brelsford, 2012). However, if the signal detected in our topologies resulted from secondary contact, we would also expect to find demographic expansion in the southern group creating a hybridization zone in the region of the middle São Francisco River, with a more heterogeneous signal of haplotype and nucleotide diversity and a greater number of haplotypes shared between the southern and northern populations (Sequeira et al., 2011), although we found weak evidence of this in our data. This hypothesis cannot be discarded altogether, given the phylogeographical patterns in the genetic structure of lizards (Werneck et al., 2015) and rodents (Nascimento et al., 2013), which have demonstrated the potential existence of the past connections between the opposite margins of the São Francisco River, coinciding with the region occupied by the western clade of $P$. nordestinus.

These connections are validated by the paleological evidence of the increasingly hot and dry climate in the region following the LGM, which led to a reduction in the volume of water in the middle São Francisco River. These conditions also favored the expansion of the Caatinga and would have resulted in contact between opposite margins of the São Francisco in western Bahia. The islands found in the river at Xique-Xique are considered to be a relic of this period of Pleistocene climatic change (Barreto, 1996; Nascimento et al., 2013), and additional sampling of $P$. nordestinus in this region may provide important insights into the existence of a possible secondary contact zone between the northern and southern lineages.

\section{CONCLUSION}

Our data support the riverine barrier model as the origin of the genetic structure detected among $P$. nordestinus populations, in particular the historical shifts in the course of the São Francisco River. This river has acted as a physical barrier to gene flow between populations from opposite margins, resulting in the lineage divergence observed. In addition, we found evidence that genetic differences were reinforced by Pleistocene climate oscillations, which includes a genomic signature of post-LGM demographic population expansion. Despite the fact that phylogenetic systematics were beyond the scope of this paper, we can only emphasize the need for a complete taxonomic review of the species, including the definition of species ranges and morphological diagnoses, once that our data revealed two units that have evolved independently. The recognition of these two independent lineages also has important implications for their conservation in northeastern Brazil as well as for the understanding of ecological and evolutionary patterns, in particular the patterns of species diversification in the Atlantic Forest.

\section{ETHICS STATEMENT}

The examined specimens were collected with appropriate permission under authorization number 14468-1/14468-4 
issued by SISBIO/Instituto Chico Mendes de Conservação da Biodiversidade. For the subsequent techniques, all tissue sampling were extracted from euthanized specimens using anesthetic application over the skin (5\% Lidocaine) to minimize animal suffering, according to recommendations of the Herpetological Animal Care and Use Committee (HACC) of the American Society of Ichthyologists and Herpetologists (available at: http://www.asih.org/publications), and approved by SISBIO/ Institute Chico Mendes de Conservação da Biodiversidade during the process of the concession license.

\section{AUTHOR CONTRIBUTIONS}

DB: designed and coordinated the study of molecular data, provided molecular dataset, analysed the data, and draft the manuscript. EP: analysed the data, discuss results and helped draft the manuscript. LL: discuss results and helped draft the manuscript. LB: ABC analysis and helped draft the manuscript. TS-S: ENM analysis and helped draft the manuscript. SMRP: designed and coordinated the study of molecular data, discuss results and helped draft results. All authors have read and approved the final version submitted.

\section{ACKNOWLEDGMENTS}

We thank the Fundação de Amparo à Pesquisa do Estado de São Paulo (FAPESP; grants 2010/17464-1 and 2012/12169-7), Conselho Nacional de Desenvolvimento Científico e Tecnológico

\section{REFERENCES}

Álvarez-Presas, M., Sanchez-Gracia, A., Carbayo, F., Rozas, J., and Riutort, M. (2014). Insights into the origin and distribution of biodiversity in the Brazilian Atlantic forest hot spot: a statistical phylogeographic study using a low dispersal organism. Heredity 112, 656-665. doi: 10.1038/hdy.2014.3

Allouche, O., Tsoar, A., and Kadmon, R. (2006). Assessing the accuracy of species distribution models: prevalence, kappa and the true skill statistic (TSS). J. Appl. Ecol. 43, 1223-1232. doi: 10.1111/j.1365-2664.2006.01214.x

Amaral, F. R., Albers, P. K., Edwards, S., and Miyaki, C. Y. (2013). Multilocus tests of Pleistocene refugia and ancient divergence in a pair of Atlantic Forest antbirds (Myrmeciza). Mol. Ecol. 22, 3996-4013. doi: 10.1111/mec.12361

Araújo, M. B., and New, M. (2007). Ensemble forecasting of species distributions. Trends Ecol. Evol. 22, 42-47. doi: 10.1016/j.tree.2006.09.010

Arenas, M., Mona, S., Trochet, A., Sramkova Hanulova, A., Currat, M., Ray, N., et al. (2014). The scaling of genetic diversity in a changing and fragmented world. In "Scaling in Ecology and Biodiversity Conservation". Eds., Henle K, Potts SG, Kunin WE, Matsinos YG, Similä J, Pantis JD, Grobelnik V, Penev L, Settele J. Sofia: Pensoft Publishers. Pp. 55-60.

Arenas, M., Ray, N., Currat, M., and Excoffier, L. (2012). Consequences of range contractions and range shifts on molecular diversity. Mol. Biol. Evol. 29 (1), 207-218. doi: 10.1093/molbev/msr187

Barreto, A. M.F. (1996). Interpretacão paleoambiental do sistema de dunas fixadas do me'dio Rio Saão Francisco, Bahia [PhD]. Saão Paulo: Universidade de São Paulo.

Bandelt, H. J., Forster, P., and Röhl, A. (1999). Median-joining networks for inferring intraspecific phylogenies. Mol. Biol. Evol. 16, 37-48. doi: 10.1093/ oxfordjournals.molbev.a026036

Barve, N., Barve, V., Jiménez-Valverdade, A., Lira-Noriega, A., Maher, S. P., Peterson, A. T., et al. (2011). The crucial role of the accessible area in ecological
(CNPq), and Coordenadoria de Aperfeiçoamento de Pessoal de Nível Superior (CAPES) for scholarships to DPB thank FAPESP for scholarships (FAPESP 10/17464-1). TSS thank CNPq for postdoc fellowship (process number 150319/2017-7). The authors thank Célio F. B. Haddad for the loan of tissues, Michel Aguiar Passos and Jonatha Lima for the assistance with collecting for this study, and members of the Estudos Cromossômicos Lab for assistance with lab work. We especially thank Kelly R. Zamudio for his helpful comments during this research and for valuable comments on a previous version of the manuscript. Lab work was conducted in Departamento de Biologia Estrutural e Funcional da Unicamp, and computational analyses benefited from the support of Cornell's Biological Service Unit.

\section{SUPPLEMENTARY MATERIAL}

The Supplementary Material for this article can be found online at: https://www.frontiersin.org/articles/10.3389/fgene.2019.00728/ full\#supplementary-material

FIGURE S1 | Bayesian Analyses of Population Structure (BAPS) results. The colors represent the subdivisions indicated, and the mitochondrial results are shown in Figure 3.

FIGURE S2 | Mitochondrial and nuclear tree obtained in *BEAST analysis. (A) $16 \mathrm{~S}$ gene; (B) ND2; (C) SiaH; (D) Rhod.

FIGURE S3 | Confusion matrix generated by the cross-validation performed using the "abc" package on R.

FIGURE S4 | Goodness-of-fit PCA analysis of the summary statistics simulated under Model 2.

niche modeling and species distribution modeling. Ecol. Modell. 222, 18101819. doi: 10.1016/j.ecolmodel.2011.02.011

Batalha-Filho, H., Cabanne, G.S., and Miyaki, C. Y. (2012). Phylogeography of an Atlantic Forest passerine reveals demographic stability through the last glacial maximum. Mol. Phylogenet. Evol. 65, 892-902. doi: 10.1016/j.ympev.2012.08.010.

Bruschi, D.P., Busin, C.S., Siqueira, S., and Recco-Pimentel, S.M. (2012) Cytogenetic analysis of two species in the Phyllomedusa hypochondrialis group (Anura, Hylidae). Hereditas 149(1), 34-40. doi: 10.1111/j.1601-5223.2010.02236.x

Cabanne, G., Calderón, L., Trujillo, A.N., Flores, P., Pessoa, R., d'Horta, F., et al. (2016). Effects of Pleistocene climate changes on species ranges and evolutionary processes in the Neotropical Atlantic Forest. Biol. J. Lin. Soc. 119, 856-872. doi: 10.1111/bij.12844

Caldas, F. L. S., Silva, B. D., Santos, R. A., De-Carvalho, C. B., Santana, D. O., Gomes, F. F. A., et al. (2014). Autoecology of Phyllomedusa nordestina (Anura: Hylidae) in areas of the Caatinga and Atlantic Forest in the State of Sergipe, Brazil. North-West. J. Zool. 12 (2), 271-285.

Caramaschi, U. (2006). Redefinição do grupo de Phyllomedusa hypochondrialis, com redescrição de P. megacephala (Miranda-Ribeiro, 1926), revalidação de P. azurea Cope, 1826 e descrição de uma nova espécie (Amphibia, Anura, Hylidae). Arq. Mus. Nac. 64, 159-179.

Carnaval, A. C. O. Q., and Moritz, C. (2008). Historical climate modeling predicts patterns of current biodiversity in the Brazilian Atlantic Forest. J. Biogeogr. 35, 1-15. doi: 10.1111/j.1365-2699.2007.01870.x

Carnaval, A. C., Hickerson, M. J., Haddad, C. F. B., Rodrigues, M. T., and Moritz, C. (2009). Stability predicts genetic diversity in the Brazilian Atlantic forest hotspot. Science 323, 785-789. doi: 10.1126/science.1166955

Carpenter, G., Gillison, A. N., and Winter, J. (1993). DOMAIN: a flexible modeling procedure for mapping potential distributions of animals and plants. Biodivers. Conserv. 2, 667-680. doi: 10.1007/BF00051966 
Cazé, A. L. R., Mäder, G., Nunes, T. S., Queiroz, L. P., Oliveira, G., Diniz-Filho, J. A. F., et al. (2016). Could refuge theory and rivers acting as barriers explain the genetic variability distribution in the Atlantic Forest? Mol. Phylogenet. Evol. 101, 242-251. doi: 10.1016/j.ympev.2016.05.013

Corander, J., Sirén, J., and Arjas, E. (2008). Bayesian spatial modeling of genetic population structure. Comput. Stat. 23, 111-129. doi: 10.1007/ s00180-007-0072-x

Coutinho-Abreu, I. V., Sonoda, I. V., Fonseca, J. A., Melo, M. A., Balbino, V. Q., and Ramalho-Ortigão, M. (2008). Lutzomyia longipalpis s.l. in Brazil and the impact of the Sao Francisco River in the speciation of this sand fly vector. Parasit. Vectors 1, 16.

Crawford, A. J. (2003). Huge populations and old species of Costa Rican and Panamanian dirt frogs inferred from mitochondrial and nuclear gene sequences. Mol. Ecol. 12, 2525-2540. doi: 10.1046/j.1365-294X.2003.01910.x

Csilléry, K., Franc, ois, O., and Blum, M. G. B. (2012). abc: an R package for approximate Bayesian computation (ABC). Methods Ecol. Evol. 3(3), 475-479. doi: 10.1111/j.2041-210X.2011.00179.x

Dantas, G. P. M., Sari, E. H. R., Cabanne, G. S., Pessoa, R. O., Marini, M. A., Miyaki, C. Y., et al. (2014). Population genetic structure of the Atlantic Forest endemic Conopaphaga lineata (Passariformes: Conopophagidae) reveals a contact zone in the Atlantic Forest. J. Ornotol. 156, 85-99. doi: 10.1007/s10336-014-1106-0

Diniz-Filho, J. A. F., Bini, L. M., Rangel, T. F., Loyola, R. D., Hof, C., Nogués-Bravo, D., et al. (2009). Partitioning and mapping uncertainties in ensembles of forecasts of species turnover under climate change. Ecography 32, 897-906. doi: 10.1111/ j.16000587.2009.06196.x

Drummond, A. J., Suchard, M. A., Xie, D., and Rambaut, A. (2012). Bayesian phylogenetics with BEAUti and the BEAST 1.7. Mol. Biol. Evol. 29, 1969-1973. doi: $10.1093 / \mathrm{molbev} / \mathrm{mss} 075$

Duellman, W.E., Marion, A.B., and Hedges, S. B. (2016). Phylogenetics, classification, and biogeography of the treefrogs (Amphibia: Anura: Arboranae). Zootaxa 4104(1), 001-109. doi: 10.11646/zootaxa.4104.1.1

Edgar, R. C. (2004). MUSCLE: multiple sequence alignment with high accuracy and high throughput. Nucleic Acids Res. 32, 1792-1797. doi: 10.1093/nar/ gkh340

Excoffier, L., and Lischer, H. E. L. (2010). Arlequin suite ver 3.5: a new series of programs to perform population genetics analyses under Linux and Windows. Mol. Ecol. Resour. 10, 564-567. doi: 10.1111/j.1755-0998.2010.02847.x

Excoffier, L., Smouse, P. E., and Quattro, J. M. (1992). Analysis of molecular variance inferred from metric distances among DNA haplotypes: application to human mitochondrial DNA restriction data. Genetics 131, 479-491.

Faivovich, J., Haddad, C. F. B., Baêta, D., Jungfer, K. H., Álvares, G. F. R. A., Brandão, R. A., et al. (2010). The phylogenetic relationships of the charismatic poster frogs, Phyllomedusinae (Anura, Hylidae). Cladistics 25, 1-35. doi: 10.1111/j.1096-0031.2009.00287.x

Frantini-Silva, W., Giangarelli, D. C., Penha, R. E. S., Suzuki, K. M., Gaglianone, M. C., Alves-dos-Santos, I., et al. (2017). Phylogeography and historical demography of the orchid bee Euglossa iopoecila: signs of vicariant events associated to Quaternary climatic changes. Conserv. Genet. 18, 539-552. doi: 10.1007/s10592-016-0905-7

Farber, O., and Kadmon, R. (2003). Assessment of alternative approaches for bioclimatic modeling with special emphasis on the Mahalanobis distance. Ecol. Modell. 160, 115-130. doi: 10.1016/S0304-3800(02)00327-7

Flot, J. F. (2010). SEQPHASE: a web tool for interconverting phase input/output files and fasta sequence alignments. Mol. Ecol. Resour. 10, 162-166. doi: 10.1111/j.1755-0998.2009.02732.x

Frost, D. R. (2019). Amphibian species of the world: an online reference. Version 6.0. http://research.amnh.org/herpetology/amphibia/index.html (Accessed July 22, 2019)

$\mathrm{Fu}$, Y. X. (1997). Statistical tests of neutrality of mutations against population growth, hitchhiking and background selection. Genetics 147, 915-925.

Funk, D. J., and Omland, K. E. (2003). Species-level paraphyly and polyphyly: frequency, causes, and consequences, with insights from animal mitochondrial DNA. Annu. Rev. ecol. Syst. 34, 397-423. doi: 10.1146/annurev. ecolsys.34.011802.132421

Haffer J. (1969). Speciation in Amazonian forest birds. Science 165, 131-137.

Harpending, H. C. (1994). Signature of ancient population growth in a lowresolution mitochondrial DNA mismatch distribution. Hum. Biol. 66, 591-600.
Heled, J., and Drummond, A. J. (2008). Bayesian inference of population size history from multiple loci. BMC Evol. Biol. 8, 289. doi: 10.1186/1471-2148-8-289

Heled, J., and Drummond, A. J. (2010). Bayesian inference of species trees from multilocus data. Mol. Biol. Evol. 27, 570-580. doi: 10.1093/molbev/msp274

Hudson, R. R. (2002). Generating samples under a Wright-Fisher neutral model of genetic variation. Bioinformatics 18, 337-338. doi: 10.1093/ bioinformatics/18.2.337

Katoh, K., and Standley, D. M. (2013). MAtlantic ForestFT multiple sequence alignment software version 7: improvements in performance and usability. Mol. Biol. Evol. 30, 772-780. doi: 10.1093/molbev/mst010

King, L. C. (1956). A geomorfologia do Brasil oriental. Revista Brasileira de Geografia 2, 3-47.

Leigh, J. W., and Bryant, D. (2015). Popart: full-feature software for haplotype network construction. Methods Ecol. Evol. 6, 1110-1116. doi: 10.1111/2041210X.12410

Lemmon, E. M., Lemmon, A. R., and Canatella, D. C. (2007). Geological and climatic forces driving speciation in the continentally distributed trilling chorus frogs (Pseudacris). Evolution 61(9), 2086-2103. doi: 10.1111/j.1558-5646.2007.00181.x

Librado, P., and Rozas, J. (2009). DnaSP v5: a software for comprehensive analysis of DNA polymorphism data. Bioinformatics 25, 1451-1452. doi: 10.1093/ bioinformatics/btp187

Liebgold, E. B., Brodie, E. D., and Cabe, P. R. (2011). Female philopatry and malebiased dispersal in a direct-developing salamander, Plethodon cinereus. Mol. Ecol. 20, 249-257. doi: 10.1111/j.1365-294X.2010.04946.x

Lima, C. C. U., Bezerra, F. H. R., Nogueira, F. C. C., Maia, R. P., and Sousa, M. O. L. (2014). Quaternary fault control on the coastal sedimentation and morphology of the São Francisco coastal plain, Brazil. Tectonophysics 633, 98-114. doi: $10.1016 /$ j.tecto.2014.06.026

Liu, C., Newell, G., and White, M. (2016). On the selection of thresholds for predicting species occurrence with presence-only data. Ecol. Evol. 6, 337-348. doi: $10.1002 /$ ece3.1878

Magalhães, I. L. F., Oliveira, U., Santos, F., Vidigal, T. H. D. A., Brescovits, A. D., and Santos, A. J. (2014). Strong spatial structure, Pliocene diversification and cryptic diversity in the Neotropical dry forest spider Sicarius cariri. Mol. Ecol. 23, 5323-5336. doi: 10.1111/mec. 12937

Mabesoone, J. M. (1994). Sedimentary basins of northeast Brazil. Federal University of Pernambuco, 310pp: Recife.

Menezes, L., Canedo, C., Batalha-Filho, H., Garda, A. A., Gehara, M., and Napoli, M. F. (2016). Multilocus phylogeography of the treefrog Scinax eurydice (Anura, Hylidae) reveals a Plio-Pleistocene diversification in the Atlantic Forest. PLoS ONE 11 (6), e0154626. doi: 10.1371/journal.pone.0154626

Mona, S., Ray, N., Arenas, M., and Excoffier, L. (2014). Genetic consequences of habitat fragmentation during a range expansion. Heredity 112, 291-299. doi: 10.1038/hdy.2013.105

Moritz, C., Patton, J. L., Schneider, C. J., and Smith, T. B. (2000) Diversification of rainforest faunas: an integrated molecular approach. Annu. Rev. ecol. Syst. 31, 533-563. doi: 10.1146/annurev.ecolsys.31.1.533

Nascimento, F. F., Lazar, A., Menezes, A. N., Durans, A. D. M., Moreira, J. C., Salazar-Bravo, J., et al. (2013). The role of historical barriers in the diversification processes in open vegetation formations during the Miocene/Pliocene using an ancient rodent lineage as a model. PLoS ONE 8 (4), e61924. doi: 10.1371/ journal.pone.0061924

Nascimento, F. F., Pereira, L. G., Geise, L., Bezerra, A. M. R., D'Andrea, P. S., and Bonvicino, C. R. (2011). Colonization process of the Brazilian common vesper mouse, Calomys expulsus (Cricetidae, Sigmodontinae): a biogeographic hypothesis. J. Hered. 102(3), 260-268. doi: 10.1093/jhered/esr012

Nix, H. (1986). "A biogeographic analysis of Australian Elapid snakes," in Snakes: Atlas of Elapid snakes of Australia. Ed. R. Longmore (Canberra: Bureau of Flora and Fauna), 4-10.

Otto-Bliesner, B., Marshall, S. J., Overpack, J. T., Miller, G. H., and Hu, A. (2006). Simulating arctic climate warmth and icefield retreat in the last interglaciation. Science 24, 1751-1753. doi: 10.1126/science.1120808

Passoni, J. C., Benozzati, M. L., Rodrigues M. T. (2008). Phylogeny, species limits, and biogeography of the Brazilian lizards of the genus Eurolophosaurus (Squamata: Tropiduridae) as inferred from mitochondrial DNA sequences. Mol. Phylogenetics. Evol. 46, 403-414. doi: 10.1016/j.ympev.2007.10.022

Pelegrino, K. C. M., Rodrigues, M.T., Waite, A. N., Morando, M., Yassuda, Y. Y., Sites Jr, J. W. (2005). Phylogeography and species limits in the Gymnodactylus 
darwinii complex (Gekkonidae, Squamata): genetic structure coincides with river systems in the Brazilian Atlantic Forest. Biol. J. Linn. Soc. 85, 13-26. doi: 10.1111/j.1095-8312.2005.00472.x

Peres, E. A., DaSilva, M. B., Antunes, M. Jr., and Pinto-Da-Rocha, R. (2018). Short-range endemic species from south-eastern Atlantic Rain Forest shows deep signature of historical events: phylogeography of harvestmen Acutisoma longipes (Arachnida: Opiliones). Syst. Biodivers. 162 (2), 171-187. doi: 10.1080/ 14772000.2017.1361479

Phillips, S. J., and Dudik, M. (2008). Modeling of species distributions with Maxent: new extensions and a comprehensive evaluation. Ecography 31, 161175. doi: $10.1111 /$ j.0906-7590.2008.5203.x

Prugnolle, F., and Meeus, T. (2002). Inferring sex-biased dispersal from population genetic tolls: a review. Heredity 88, 161-165. doi: 10.1038/sj.hdy.6800060

Potter, P. E. (1997). The Mesozoic and Cenozoic paleodrainage of South America: a natural history. J. S. Am. Earth Sci. 10 (5-6), 331-344. doi: 10.1016/S08959811(97)00031-X

Ramos-Onsins, S. E., and Rozas, J. (2000). Statistical properties of new neutrality tests against population growth. Mol. Biol. Evol. 19, 2092-2100. doi: 10.1093/ oxfordjournals.molbev.a004034

Rodrigues, M. T. (1996). Lizards, snakes, and amphisbaenians from the Quaternary sand dunes of the middle Rio São Francisco, Bahia, Brazil. J. Herpetol. 30, 513523. doi: $10.2307 / 1565694$

Rodrigues, M. T., and Juncá, F. A. (2006). Herpetofauna of the Quaternary sand dunes of the middle Rio São Francisco: Bahia: Brazil. VII. Typhlops amoipira sp. nov., A possible relative of Typhlops yonenagae (Serpentes, Typhlopidae). Papéis Avulsos de Zoologia 42, 325-333.

Rogers, A. R., and Harpending, H. C. (1992). Population growth makes waves in the distribution of pairwise genetic differences. Mol. Biol. Evol. 9, 552-569.

Rull, V. (2011). Neotropical biodiversity: timing and potential drivers. Tree 26, 508-513. doi: 10.1016/j.tree.2011.05.011

Sequeira, F., Sodré, D., Ferrand, N., Bernardi, J. A. R., Sampaio, I., Schneider, H., et al. (2011). Hybridization and massive mtDNA unidirectional introgression between the closely related Neotropical toads Rhinella marina and R. schneideri inferred from mtDNA and nuclear markers. BMC Evol. Biol. 11, 264. doi: 10.1186/1471-2148-11-264

Siedchlag, A. C., Benozzati, M. L., Passoni, J. C., and Rodrigues, M. T. (2010). Genetic structure, phylogeny, and biogeography of Brazilian eyelidless lizards of genera Calyptommatus and Nothobachia (Squamata, Gymnophthalmidae) as inferred from mitochondrial DNA sequences. Mol. Phylogenet. Evol. 56, 622-630. doi: 10.1016/j.ympev.2010.04.027

Sobral-Souza, T., Francini, R. B., and Lima-Ribeiro, M. S. (2015). Species extinction risk might increase out of reserves: allowances for conservation of threatened butterfly Actinote quadra (Lepidoptera: Nymphalidae) under global warming. Nat. Conservacao 13, 159-165. doi: 10.1016/j.ncon.2015.11.009

Stephens, M., and Donnelly, P. A. (2003). A comparison of Bayesian methods for haplotype reconstruction from population genotype data. Am. J. Hum. Genet. 73, 1162-1169. doi: $10.1086 / 379378$
Tajima, F. (1989). Statistical method for testing the neutral mutation hypothesis by DNA polymorphism. Genetics 123, 585-595.

Tamura, K., Stecher, G., Peterson, D., Filipski, A., and Kumar, S. (2013). MEGA6: molecular evolutionary genetics analysis version 6.0. Mol. Biol. Evol. 30, 27252729. doi: $10.1093 / \mathrm{molbev} / \mathrm{mst} 197$

Tax, D. M. J., and Duin, R. P. W. (2004). Support vector data description. Mach. Learn. 54, 45-66. doi: 10.1023/B:MACH.0000008084.60811.49

Thomé, M.T.C., Zamudio, K.R., Giovanelli, J.G.R., Haddad, C.F.B., Baldissera, F.A. Jr., and Alexandrino, J. (2010). Phylogeography of endemic toads and postPliocene persistence of the Brazilian Atlantic Forest. Mol. Phylogenet. Evol. 55, 1018-1031. doi: 10.1016/j.ympev.2010.02.003

Thomé, M. T., Zamudio, K. R., Haddad, C. F. B., and Alexandrino, J. (2014). Barriers, rather than refugia, underlie the origin of diversity in toads endemic to the Brazilian Atlantic Forest. Mol. Ecol. 23, 6152-6164. doi: 10.1111/ mec. 12986

Toews, D. P. L., and Brelsford, A. (2012). The biogeography of mitochondrial and nuclear discordance in animals. Mol. Ecol. 21, 3907-3930. doi: 10.1111/j. 1365-294X.2012.05664.x

Tsai, Y. H. E., and Carstens, B. C. (2013). Assessing model fit in phylogeographical investigations: an example from the North American sandbar willow Salix melanopsis. J. Biogeogr. 40, 131-141. doi: 10.1111/j.1365-2699.2012.02775.x

Turchetto-Zolet, A. C., Pinheiro, F., Salgueiro, F., and Palma-Silva, C. (2013). Phylogeographical patterns shed light on evolutionary process in South America. Mol. Ecol. 22, 1193-1213. doi: 10.1111/mec.12164

Vanzolini, P. E., and Williams, E. E. (1981). The vanishing refuge: a mechanism for ecogeographic speciation. Pap. Avulsos Zool. 34 (23), 251-255.

Wallace, A. R. (1852). On the monkeys of the Amazon. Proc. Zool. Soc. London 20, 107-110.

Werneck, F. P., Gamble, T., Colli, G. R., Rodrigues, M.T., and Sites, J. W. (2012). Deep diversification and long-term persistence in the South American 'dry diagonal': integrating continent-wide phylogeography and distribution modeling of geckos. Evolution 66, 3014-3034. doi: 10.1111/j.1558-5646.2012.01682.

Werneck, F., Leite, R. N., Geurgas, S. R., and Rodrigues, M. T. (2015). Biogeographic history and cryptic diversity of saxicolous Tropiduridae lizards endemic to the semiarid Caatinga. BMC Evol. Biol. 15, 94. doi: 10.1186/s12862-015-0368-3

Conflict of Interest Statement: The authors declare that the research was conducted in the absence of any commercial or financial relationships that could be construed as a potential conflict of interest.

Copyright (C) 2019 Bruschi, Peres, Lourenço, Bartoleti, Sobral-Souza and ReccoPimentel. This is an open-access article distributed under the terms of the Creative Commons Attribution License (CC BY). The use, distribution or reproduction in other forums is permitted, provided the original author(s) and the copyright owner(s) are credited and that the original publication in this journal is cited, in accordance with accepted academic practice. No use, distribution or reproduction is permitted which does not comply with these terms. 